\title{
UTILIZAÇÃO DO FACEBOOK PELOS GOVERNOS LOCAIS PARA PROMOÇÃO DE ACCOUNTABILITY COM PARTICIPAÇÃO SOCIAL
}

\section{FACEBOOK'S USE BY LOCAL GOVERNMENTS TO PROMOTE ACCOUNTABILITY WITH SOCIAL PARTICIPATION}

\author{
Osmar Siena ${ }^{1}$ \\ Erasmo Moreira de Carvalho \\ Priscila de Oliveira Borba ${ }^{3}$
}

\section{Resumo}

Considerando a popularidade das mídias sociais, suas funcionalidades e o déficit de accountability e participação social nas esferas governamentais, apontado por estudos acadêmicos e perceptível pelo senso comum, esta pesquisa tem como objetivo verificar em que medida a gestão dos governos locais estão se utilizando do Facebook enquanto canal de comunicação para a promoção e fortalecimento de accountability com participação social. Para o cumprimento desse propósito, o pressuposto filosófico que rege a pesquisa é o pós-positivismo, sendo o método de pesquisa qualitativo descritivo e como estratégia a pesquisa de campo virtual. O processo de coleta de dados se deu por meio de observação não participante on-line e os dados foram analisados utilizando a técnica de análise de conteúdo. Os resultados da pesquisa apresentam indícios de que as gestões municipais fazem uso do Facebook, limitadamente para fins de informação pública, praticando um tipo de comunicação assimétrica e de mão única. Os achados demonstram que estas administrações municipais não se aproveitam dos affordances da mídia social em estudo para promoção e fortalecimento da participação social e para viabilização de uma comunicação simétrica e de mão dupla.

Palavras-chave: accountability. comunicação pública. Facebook. Participação.

\footnotetext{
${ }^{1}$ Mestrado Profissional Interdisciplinar em Direitos Humanos e Desenvolvimento da Justiça - DHJUS/UNIR. Programa de Pós-Graduação: Mestrado em Administração - PPGMAD/UNIR. Departamento de Administração - UNIR. Universidade Federal de Rondônia - UNIR. Brasil. E-mail: siena@unir.br

2 Professor Adjunto do Departamento de Ciências Contábeis e do Mestrado Profissional em Administração Pública da Universidade Federal de Rondônia - UNIR. Universidade Federal de Rondônia - UNIR. Brasil. E-mail: erasmo@unir.br

${ }^{3}$ Relações Públicas da Universidade Federal de Rondônia - UNIR. Universidade Federal de Rondônia - UNIR. Brasil. E-mail: priscila.borba@unir.br
} 


\section{Abstract}

Considering the popularity and functionality of social media, as well the lack of accountability and social participation in the governmental spheres which was identified by preceding researches and perceptible by common sense, this research aims to analyze in which extent the local governments' management are using Facebook as a communication channel for the promotion and strengthening of accountability with social participation. In order to fulfill this purpose, this paper adopted postpositivism as philosophical presupposition, the method conducted was qualitative descriptive research, and the strategy was the virtual field research. The data collection was processed through online non-participant observation and the data were analyzed using the technique of content analysis. The results of the research show that the municipal administrations use Facebook partially for public information limited purpose, practicing an asymmetric and single-handed type of communication. The findings show that municipal administrations do not take affordances advantage from social media to promote and strengthen social participation and to enable symmetrical communication.

Keywords: accountability. public communication. Facebook. Participation.

\section{INTRODUÇÃO}

A estrutura organizacional da sociedade e o processo de comunicação têm sofrido mudanças significativas com a inserção das Tecnologias Digitais de Informação e Comunicação (TICs), com destaque à popularização da internet a partir da década de 1990 (CASTELLS, 2002).

Segundo o último relatório disponibilizado pela União Internacional de Telecomunicações, aproximadamente $60 \%$ da população mundial possui acesso à internet (UIT, 2017). No Brasil, cerca de 66\% dos brasileiros usam a internet (STATISTA, 2018). A rede está presente nos domicílios de todas as regiões brasileiras: Sudeste, $76,7 \%$ das residências possuem acesso à internet; CentroOeste, 74,7\%; Sul, 71,3\%; Norte, 62,4\%; e Nordeste, 56,6\% (IBGE, 2016).

Aproximadamente $58 \%$ da população brasileira usufrui das mídias sociais. O Facebook é a mídia social mais utilizada no mundo com mais de 2 bilhões de usuários ativos, desses 130 milhões estão no Brasil (STATISTA, 2018).

Redes sociais são as interações, os relacionamentos existentes entre as pessoas enquanto as mídias sociais são as plataformas digitais utilizadas para estabelecer essas redes de 
relacionamentos. Portanto, os conceitos de mídias sociais e de redes sociais são distintos (RECUERO, 2009),

Estudos demonstram que as mídias socias estão sendo utilizadas em todos os tipos de organizações: privadas (e.g. DREYER, 2014; ROSA; RUSSEL, 2011), terceiro setor (e.g. WATERS et al., 2009) e organizações públicas (e.g. SANTOS; SILVA, 2017; NASCIMENTO, 2014; ROCHA JR, 2017). Há a partir de 2010 uma ascensão na utilização das mídias sociais pelo governo, acredita-se que no intuito de alcançar o envolvimento e a participação do cidadão com a gestão pública (MAGRO; 2012). Este crescimento quanto a utilização de mídias sociais também pode estar ocorrendo pelo fato de que esses canais de comunicação possuem affordances ${ }^{1}$ que possibilitam a accountability e a participação social, tais como: comunicabilidade, que permite uma linguagem única para a comunicação; interatividade, que promove um espaço de interação entre o governo e a sociedade; visibilidade, que propicia a transparência para os cidadãos, além de detectar suas opiniões, necessidades e desejos; habilidade colaborativa, que disponibiliza um espaço para que os cidadãos e o governo compartilhem informações importantes para a tomada de decisões; e anonimato, que permite ao cidadão expressar-se sem a necessidade de identificação, fazendo com que ele participe sem nenhuma forma de opressão (STAMATI; PAPADOPOULOS; ANAGNOSTOPOULOS, 2014). Estas funcionalidades não são típicas de outras plataformas digitais tradicionais, utilizadas pelos governos, com a mesma dimensão e propriedade com que se fazem presentes nas mídias sociais.

A literatura tem demonstrado os benefícios da utilização das mídias sociais pelo setor público, sendo destacadas, dentre outras: a eficiência, a transparência, a participação (BERTOT; JAEGER; GRIMES, 2011), a promoção de confiança no governo pelo cidadão, a melhoria da democracia e da accountability (PICAZO-VELA; GUTIÉRREZ-MARTÍNEZ; LUNA-REYES, 2012). Por ouro lado, outros estudos demonstram certas preocupações em razão da exclusão digital (MAGRO, 2012) e da forma de utilização dessas ferramentas (NOGUEIRA; CASTRO, 2014; ZHENG; ZHENG, 2014).

As organizações públicas nas Américas (e.g. BERTOT; JAEGER; GRIMES, 2011), na Ásia (e.g. ZHENG; ZHENG, 2014) e na Europa (e.g. BONSÓN; ROYO; RATKAY, 2014; STAMATI; PAPADOPOULOS; ANAGNOSTOPOULOS, 2014) identificaram nas mídias sociais ambientes propícios para operacionalizar a accountability e ampliar a comunicação com os seus públicos por meio dessas plataformas.

No Brasil, as mídias sociais estão sendo empregadas de forma ampla pelos três poderes: executivo, legislativo e judiciário, e, em todos os níveis de governo. A última pesquisa realizada pelo Comitê Gestor da Internet no Brasil, em 2015, verificou que 92\% dos órgãos da administração pública 
federal, $74 \%$ dos órgãos estaduais e $66 \%$ dos municipais estavam ativos nas mídias sociais. 0 Facebook, além de ser a mídia social com maior número de usuários no Brasil, também é a mídia mais utilizada na administração pública brasileira (CGI, 2016).

No intuito de promover uma comunicação pública mais transparente e participativa nas instituições públicas, foram criadas várias leis, tais como: Lei de Responsabilidade Fiscal (LRF) - Lei Complementar no 101/2000, que estabelece normas de finanças públicas voltadas para a responsabilidade na gestão fiscal (BRASIL, 2000); Lei Complementar no 131/2009, que altera dispositivos da LRF no que tange à transparência da gestão fiscal; e Lei de Acesso à Informação (LAI) - Lei no 12.527/2011, que assegura o direito constitucional de acesso às informações públicas. No entanto, nenhum desses normativos cuidam de forma geral ou específica de comunicação pública governamental por meio de mídias sociais, talvez por ser um fenômeno recente. Ou, simplesmente, os responsáveis pela formulação de políticas públicas não perceberam, ainda, a necessidade de regulamentar a utilização destas ferramentas pelo setor público.

Mesmo considerando este cenário tecnológico e regulatório os estudos nacionais sobre a comunicação pública entre governo e sociedade, em todas as suas esferas, apontam para um déficit de accountability e participação social (e.g. PINHO, 2008; RAUPP E PINHO, 2013; ANGELI, 2017; NASCIMENTO, 2014; NOGUEIRA E CASTRO, 2014; ROCHA JR, 2017).

Assim, conforme evidenciado anteriormente, a popularidade das mídias sociais, suas funcionalidades e o déficit de accoutability, que a academia e o senso comum demonstram existir, em todos os níveis de governo, parece razoável levantar a proposição de que, gestores com virtudes accountable, já tenham identificado, nas mídias sociais, uma ferramenta capaz de contribuir para melhoria da democracia participativa local. Diante deste pressuposto, este estudo se propõe a verificar em que medida a gestão dos governos locais estão se utilizando do Facebook, enquanto canal de comunicação, para a promoção e fortalecimento de accountability com participação social.

\section{A COMUNICAÇÃO PÚBLICA NA ERA DIGITAL}

No final do século XX, as Tecnologias Digitais de Informação e Comunicação (TICS) acarretaram mudanças significativas no processo comunicacional e na forma de se organizar da sociedade (CASTELLS, 2002). As TICs podem ser entendidas como um conjunto de tecnologias que unem telecomunicação, transmissão via satélite, informática, telefonia móvel e internet (RAUPP; PINHO, 2013), criaram condições para a emergência da sociedade em rede (CASTELLS, 2002). Esta, de acordo com Castells (2002), é uma estrutura social globalizada, pautada no conhecimento e em 
inovações tecnológicas, estabelecida em torno de fluxos de informação, de tecnologia, de interação organizacional, de imagens, de sons e de símbolos. Essa nova forma de estruturação da sociedade acarreta impactos no cotidiano da vida humana, tais como: econômico, social, comunicacional, educacional, organizacional e político. Este estudo, de forma pontual, será discutido sob a égide dos impactos da sociedade em rede, principalmente, no que se refere ao processo comunicacional e seus efeitos na forma como as instituições governamentais estão se comunicando com seus públicos, uma vez que a sociedade em rede é caracterizada por uma comunicação horizontal, com troca de mensagens multidirecionais e interativas (TERRA, 2011).

A comunicação pública é um conceito debatido por autores internacionais (e.g. ZÉMOR, 1995; LÓPEZ, 2012; ROLANDO, 2011) e nacionais (e.g. BRANDÃO, 2007; MATOS, 2007; DUARTE, 2007). Os países europeus foram os precursores na abordagem e na práxis do conceito (DUARTE, 2007). Destaque é dado aos estudos do autor francês Pierre Zémor (1995), no qual defende que a comunicação pública tem como objetivo o "interesse geral", devendo permanecer associada aos propósitos das instituições públicas, sendo esses: a) informar, levar ao conhecimento, prestar contas; b) ouvir demandas, expectativas e necessidades; c) contribuir para garantir a relação social, o sentimento de pertencimento; e d) acompanhar as mudanças, monitorar e fiscalizar.

Nos EUA, a prática e a definição do termo estão ligadas à comunicação organizacional, enquanto na América Latina a comunicação pública possui uma perspectiva libertadora, identificada com as demandas e condutas populares (BRANDÃO, 2007). No Brasil, a comunicação pública foi, historicamente, relacionada à visibilidade e à legitimidade, possuía caráter publicitário, era marcada por uma linguagem persuasiva e tinha como objetivo criar uma imagem positiva de uma instituição ou de um gestor. Porém, desde a redemocratização do país, existe um movimento para alterar o foco dessa comunicação, no intuito de priorizar os interesses do cidadão e de garantir não apenas o direito à informação, mas também de incitar a participação e o diálogo (DUARTE, 2007). O referido autor construiu, no âmbito da comunicação pública, uma taxonomia, segundo a finalidade das informações, que se apresenta com a seguinte configuração: a) institucionais; b) de gestão; c) de utilidade pública; d) de interesse privado; e) mercadológicas; f) de prestação de contas; g) de dados públicos.

Em seus estudos sobre relações públicas nas organizações Grunig (2009a) descreve os modelos utilizados por estas para realizarem sua comunicação. De forma resumida e genérica é possível identificar dois modelos de comunicação exposto pelo autor. O primeiro modelo é descrito como aquele cujo objetivo é apenas disseminar as informações positivas, que podem ser reais ou não, e que, por vezes, são utilizadas para produzir desinformação. Neste cenário a comunicação se 
dá em mão única, assimétrica, monológica, e não existe preocupação com as necessidades dos públicos da instituição (GRUNIG, 2009a). No setor público este modelo está próximo do que se costuma denominar de transparência, disclosure, onde o fluxo de informação é apenas um - do emissor (órgão público) para os receptores (sociedade, outras organizações). O segundo é o modelo simétrico de duas mãos onde se emprega a comunicação para administrar conflitos, prestar contas, convocar o público para o diálogo, possibilitar abertura para negociações e concessões. A instituição não possui uma postura de sempre estar correta frente às situações, ela realiza uma comunicação na qual pretende ouvir e negociar com seus públicos. Esse tipo de comunicação não é somente mais eficaz, mas também mais ética perante os envolvidos (GRUNIG, 2009a). No setor governamental este processo de comunicação está mais próximo do que está se denominando, para este estudo, de participação social.

A comunicação comumente realizada pelas instituições, sejam públicas ou privadas, pautada na simples difusão de mensagens de forma persuasiva e assimétrica, vem e precisa ser substituída por configurações comunicacionais que estabelecem uma comunicação estratégica e simétrica marcada pelo diálogo (GRUNIG, 2009a). Essa necessidade fica ainda mais evidente e facilitada com o acolhimento das mídias sociais e suas habilidades interativas e dialógicas no ambiente organizacional. As organizações precisam perceber seus participantes como públicos e não simplesmente como audiência, buscando envolvê-los nas decisões, projetos, resultados e fiscalizações. Grunig (2009b) afirma que as mídias sociais possuem os affordances que auxiliam nessa mudança de paradigma.

Neste estudo compreende-se, portanto, que para a accoutability com participação, os governos locais necessitam mais do que informar, eles carecem de uma comunicação efetiva para que iniciem uma ressignificação na relação entre Estado e cidadão e isto pode ser facilitado quando comunicação pública abandona o monólogo e incorpora o diálogo como estratégia. Indo mais além, acredita-se que as mídias socias podem ser um elemento adjuvante neste contexto em função de suas vantagens de funcionalidades comunicacionais em relações as TIC's tradicionais. As mídias sociais, podem, sem demérito de outros canais de comunicação, encaminhar a inserção dos governos ao modelo de comunicação pública ideal, proposto por Grunig (2009a), o qual é baseado na interação entre os atores que se comunicam, para desta forma produzirem maior equilíbrio entre os interesses da instituição e dos seus públicos.

\section{ACCOUNTABILITY E PARTICIPAÇÃO SOCIAL}


A palavra accountability, conforme descrita por Campos (1990), não possui uma definição única e literal para o português, sendo também um processo em construção no cenário profissional brasileiro (PINHO, 2008). Na literatura, o termo accountability é utilizado como um guarda-chuva conceitual, abrigando conceitos díspares, tais como: transparência, equidade, democracia, integridade, moralidade, responsabilidade e boa governança (BOVENS, 2010). Existem vários autores com diferentes filiações disciplinares e epistemológicas que procuram elaborar sua conceituação (e.g. O'DONNEL, 1998; SCHEDLER, 1999; PERUZZOTTI; SMULOVITZ, 2002; PINHO; SACRAMENTO, 2009; BOVENS, 2010). As origens da accountability estão relacionadas aos formatos da democracia e aos modelos de administração pública empregados em vários países e isto pode ser uma das causas das acepções diferentes na utilização da expressão (GOULART, 2011).

No intuito de verificar essas várias abordagens sobre o termo no contexto da Accountability Theory, Klein (2017) realizou uma revisão sistemática da literatura e ratificou a amplitude do termo accountability e suas diversas concepções e atributos. Em síntese, para esse autor a accountability aborda a responsabilidade legal para coordenar e justificar o comportamento dos indivíduos, sendo eles responsáveis por cumprir obrigações perante audiências que tenham competência para recompensar ou sancioná-los. Alinhados com os achados desse estudo, Pinho e Sacramento (2009), ao buscarem compreender o termo por meio da literatura, assinalam que a accountability refere-se à responsabilidade objetiva, à subjetiva, ao controle e à obrigação de prestar contas e justificar ações, tendo como sua dimensão a transparência. Schedler (1999) acrescenta que a accountability além da obrigação do ator de informar sobre as ações realizadas e justificá-las, apresenta a possibilidade dele sofrer sanções, por parte de seus representados, por violação das regras pactuadas formal ou informalmente.

Em breve digressão na literatura sobre o tema é possível perceber que, de maneira geral, as definições do termo accountability estão sob a égide da Teoria da Agência, pois envolvem transparência, responsabilidade, prestação de contas, controle, fiscalização, justificativa e sanção. Todas essas tipologias estão envoltas por um ou mais contratos, formais ou simbólicos, entre os atores que se relacionam de forma complexa por meio de uma ou várias organizações (CARVALHO, 2014). Sendo esses contratos a essência da Teoria da Agência.

Uma relação de agência pode ser conceituada como aquela em que uma ou mais partes (principal) delega uma tarefa ou responsabilidade a outra (agente) para executar algo ou tomar decisões em seu nome, sendo que todas as ações delegadas pelo principal ao agente, apesar de impactarem ambas as partes, devem sempre pretender maximizar o bem-estar do principal (EISENHARDT, 1989). A abordagem principal-agente, neste estudo, concentra-se no relacionamento 
existente entre Estado-sociedade. A sociedade (principal) delega aos gestores (agente) a função de administrar o Estado para promover o seu bem-estar.

Constituindo o conceito base deste estudo e alinhado com essa perspectiva, Bovens (2010) afirma que a accountability é uma relação entre ator (agente) e fórum (principal), sendo que o ator tem a obrigação de explicar e justificar para o fórum suas ações e o fórum poderá concordar ou não com tais decisões, impondo possíveis sanções.

Assim como a accountability, o termo participação é polissêmico e se apresenta de forma diversa dependendo das vertentes teóricas e dos autores que as elaboram (LAVALLE; VERA, 2011). Em termos práticos, o fenômeno participação, assim como a accountability, é função direta do nível de maturidade da democracia de determinado Estado e da cultura democrática de seus gestores (participação como virtude). Diferentemente da accoutability, o fenômeno participação não pode ser observado ou estudado sob as lentes da Teoria da Agência. Reconhece-se que, no fenômeno participação, os atores são os mesmos e as suas funções no acordo são semelhantes ao da accountability, ou seja, o fórum (principal) que delega ações e decisões para um ator (agente), para que este as tome com fim de aumentar o bem-estar daqueles. Contudo, na participação, o fórum demanda ou the é oferecido o compartilhamento no processo decisório e executório das políticas públicas, ele não singulariza essas tarefas ao agente. Além de se responsabilizar pela fiscalização e controle, assim como na accoutability.

Nesta pesquisa é adotado o conceito de participação desenvolvido por Arnstein (1969), que se refere à redistribuição do poder aos cidadãos e compreende que a inclusão do cidadão no processo deliberativo é algo essencial para o exercício da cidadania. A referida autora argumenta que o poder deve ser compartilhado entre os cidadãos e os governantes/instituições e a sociedade deve exercer influência sobre as metas, as políticas, a alocação de recurso e o desenvolvimento de programas.

Do ponto de vista da teoria democrática percebe-se um deslocamento conceitual entre os termos: representação, participação e accountability. Devido às circunstâncias históricas, 'participação' e 'representação' ocuparam posições polares na trama da crítica democrática; 'participação' e 'accountability' não possuíam nenhuma interligação e 'representação' e 'accountability' mantinham relações estreitas (LAVALLE; VERA, 2011). Entretanto, devido às transformações recentes na representação política marcada pelo alargamento das críticas democráticas, a participação e a representação perderam suas posições polares. O governo representativo, ao passar por um processo de reconfiguração, começa a aceitar novas formas 
políticas, admitindo formas extraparlamentares de representação formal e informal (LAVALLE; VERA, 2011).

Dessa maneira, a accountability aparece como um aspecto teórico que tem o desafio de garantir legitimidade para as novas modalidades de representação política. A participação, por sua vez, se revaloriza e começa a possibilitar um senso de pertencimento do cidadão com a sociedade, que ajuda a construir uma sociedade mais justa e gera uma conexão intrínseca com a base da democracia (LAVALLE; VERA, 2011). Bobbio reforça essa visão ao afirmar que:

Em termos sintéticos, pode-se dizer que, se hoje se deve falar de um desenvolvimento da democracia, ele consiste não tanto, como erroneamente muitas vezes se diz, na substituição da democracia representativa pela democracia direta (substituição que é de fato, nas grandes organizações, impossível), mas na passagem da democracia na esfera política, isto é, na esfera em que o indivíduo é considerado como cidadão, para a democracia na esfera social, onde o indivíduo é considerado na multiplicidade de seus status, por exemplo de pai e de filho, de cônjuge, de empresário e de trabalhador, de professor e de estudante (BOBBIO, 1987, p. 156).

A perda da polarização entre representação e participação veio acompanhada de um processo de ressignificação da representação e possibilitou pensar em experiências de pluralização institucional da democracia. Possibilitou, também, iniciar a articulação de mecanismos mistos da participação, voltada para a linguagem da accountability social. Diante disso, sociedade civil, movimentos sociais e cidadãos tornam-se atores da participação direta, deliberativa democrática e política, sendo, portanto, compatíveis com governança, transparência e prestação de contas (LAVALLE; VERA, 2011).

Essa discussão resgata as formas diretas de participação do cidadão e reforça a necessidade de novos canais, para que a população tenha voz, argumente e tenha capacidade de interferir em todo o processo decisório, pautando e ajudando a desenvolver políticas públicas. Esse envolvimento do cidadão, além do processo fundamental das eleições parlamentares, caracteriza a accountability com participação (DAMGAARD; LEWIS, 2014).

\subsection{Operacionalizando a Accountability: da transparência à participação social}

\section{3..1.1 Da transparência}

De acordo com Marques (2014), o conceito de transparência não é consensual, porém existe uma concordância ainda que mínima, entre os autores, que evidencia que a transparência é fundamental para a democracia, e oferece aos cidadãos mais acesso, controle e fiscalização sobre a 
coisa pública. Ao debater sobre os conceitos mais simples até os mais complexos de transparência, Marques $(2014$, p. 6) esclarece que:

a transparência se refere à condução aberta da administração da res publica, oferecendo aos cidadãos a capacidade de controlar o Estado e a atuação de seus agentes por meio do aprimoramento das estruturas de fiscalização, de denúncia e de punição daqueles que causarem prejuízos ao interesse coletivo.

Percebe-se atualmente iniciativas por mais transparência e que, interessantemente, não estão limítrofes aos países com democracias liberais consolidadas como Reino Unido e Alemanha; ela os extrapola e tem sido percebida em novas democracias, a exemplo da África do Sul e de países não democráticos como a China (ANGELI, 2017).

O Brasil, em particular, no intuito de promover uma gestão pública mais transparente e responsável, vem implementando várias leis e normas com a finalidade de proporcionar, ao cidadão, mais informação para permitir-Ihe um controle social efetivo. Inicialmente, destaca-se o artigo 37 da Constituição Federal (CF) de 1988, que estabelece os princípios da administração pública direta e indireta: legalidade, impessoalidade, moralidade, publicidade, eficiência, eficácia e economicidade. Dentre eles, ressalta-se a publicidade que foi definida no $\S 1$ ㅇ․ A constituição determina que os governos de todas as esferas devem promover a informação de seus atos, programas, obras, serviços e campanhas (BRASIL, 1988). Depreende-se que o princípio da publicidade assegura ao cidadão o direito de saber dos atos praticados pela administração pública (ALLEGRETTI; PLATT NETO, 2010).

O ordenamento jurídico brasileiro estabelece, também, a prestação de contas das instituições públicas à comunidade. $\mathrm{O}$ artigo 70 da CF/88, em seu parágrafo único, define quem tem obrigação de prestar contas "[...] qualquer pessoa física ou jurídica, pública ou privada, que utilize, arrecade, guarde, gerencie ou administre dinheiros, bens e valores públicos ou pelos quais a União responda, ou que, em nome desta, assuma obrigações de natureza pecuniária." (BRASIL, 1988).

A criação da Lei de Responsabilidade Fiscal (LRF) - Lei Complementar no 101/2000, consolidou a transparência na administração pública brasileira, por estabelecer mecanismos e instrumentos para sua execução, baseando-se em princípios como o planejamento, a transparência e o incentivo à participação popular (PLATT NETO, 2005). O artigo 48 da LRF determina que aos instrumentos da transparência, sejam dados ampla divulgação, inclusive, por meio eletrônico de acesso público (BRASIL, 2000). Dessa forma, pode ser notada uma preocupação para que a administração pública recorra a formas mais modernas para divulgar suas informações (ALIEGRETTI; PLATT NETO, 2010). 
Outro texto legal que cabe ressaltar é a Lei de Acesso à Informação - Lei no 12.527/2011, que regulamentou o inciso XXXIII do art. 5o da CF/88 e evidenciou a relevância da transparência na administração pública (BRASIL, 2011). A LAI, além de fortalecer o incentivo à transparência pública, reforça aspectos para promover a accountability (JAHNS; RAUPP, 2016). Contudo, apenas liberar essas informações para a sociedade não assegura o entendimento e, consequentemente, não estabelece o vínculo de confiança e ligação entre Estado e cidadão. No que tange à transparência das informações, Platt Neto et al. (2007), afirmam que toda informação disponibilizada pela administração pública deve ser clara, confiável e relevante aos interesses dos usuários, apoiando o processo decisório.

Ao promoverem maior transparência, as instituições têm o dever de divulgar informações e decisões relevantes ao cidadão e incentivar a participação da sociedade na tomada de decisões (JAHNS; RAUPP, 2016). A transparência é primordial para a participação popular, pois sem informação as decisões da sociedade são prejudicadas (PLATT NETO, 2005).

\subsubsection{Da participação}

Damgaard e Lewis (2014) apresentam um quadro analítico com a possibilidade de se operacionalizar empiricamente o nível de participação do cidadão no processo de accountabilty. As autoras criaram esse framework baseadas na escala de participação de Arnstein (1969) e no conceito de accountability pública voltada para a perspectiva da aprendizagem, proposto por Bovens et al. (2008).

A escala de participação de Arnstein (1969) aborda exclusivamente a participação cidadã e explica a diferença entre 'controle cidadão' e 'manipulação'. Os tipos de participação da autora são compostos por oito níveis de participação, e iniciam-se por formas de Não Participação: manipulação e terapia; Tokenism: informação, consulta e envolvimento; e Poder Cidadão: parceria, poder delegado e controle cidadão.

Ratificando-se neste trabalho o conceito proposto por Bovens et al. (2008 e 2010), que a accountability pública voltada para a perspectiva da aprendizagem, compreende a relação entre ator (agente) e fórum (principal), sendo que o ator tem a obrigação de explicar e justificar para o fórum suas ações e o fórum poderá concordar ou não com tais decisões, caso não concorde, pode impor algumas sanções. Compreende-se a necessidade de os governos serem sensíveis às necessidades dos cidadãos, demonstrando uma atuação baseada na informação, no diálogo e no feedback. 
Diante desses conceitos, são propostas por Damgaard e Lewis (2014) cinco níveis de participação, que indicam o envolvimento dos cidadãos no quadro da accountability participativa. Nessa tipologia, os graus de participação iniciam com a não participação, caracterizada pela simples divulgação da informação 'transparência', até o nível mais elevado, descrito como um esforço colaborativo, uma governança participativa em que o cidadão está presente em todas as etapas do processo de decisão: planejamento, execução e controle, conforme explicados no quadro 1.

Antes de promover uma discussão na escala de Damgaard e Lewis (2014) é importante deixar claro que se reconhece a possibilidade da existência de outras taxonomias de participação social. Toma-se como exemplo a tipologia de participação de Pretty et al. (2005) que é muito próxima ao framework desenvolvido por Damgaard e Lewis (2014).

Quadro 1 - Níveis de participação do cidadão na accountability.

\begin{tabular}{|c|c|c|}
\hline $\begin{array}{c}\text { Níveis de } \\
\text { participação }\end{array}$ & Características da participação & $\begin{array}{l}\text { Formas de } \\
\text { participação }\end{array}$ \\
\hline Educação & $\begin{array}{l}\text { Os cidadãos recebem a informação passivamente, a qual pode } \\
\text { ser persuasiva e distorcida, direcionada para proporcionar a } \\
\text { aceitação por parte do cidadão. É exercida a comunicação de } \\
\text { mão única, impossibilitando uma participação efetiva. } \\
\text { Entretanto, esse nível torna-se essencial para a accountability } \\
\text { devido à disponibilização de dados e informações. }\end{array}$ & $\begin{array}{c}\text { Não } \\
\text { participação }\end{array}$ \\
\hline Envolvimento & $\begin{array}{l}\text { Nesse nível de participação, o cidadão monitora os processos } \\
\text { existentes, discute as informações colocadas em pauta e } \\
\text { questiona assuntos estabelecidos. Porém, não possuem poder } \\
\text { para influenciar o processo decisório. }\end{array}$ & $\begin{array}{l}\text { Participação } \\
\text { simbólica } \\
\text { "tokenism" }\end{array}$ \\
\hline Conselho & $\begin{array}{l}\text { Os cidadãos possuem tipos mais formais de influência, } \\
\text { conseguem questionar e colocar novos assuntos em pauta e } \\
\text { ainda possuem poder de julgar alguns assuntos pré- } \\
\text { estabelecidos. Inicia-se efetivamente a redistribuição do poder } \\
\text { entre os cidadãos e os tomadores de decisão. }\end{array}$ & \multirow{2}{*}{$\begin{array}{c}\text { Poder } \\
\text { cidadão }\end{array}$} \\
\hline Colaboração & $\begin{array}{l}\text { Nessa forma de participação, o cidadão consegue influenciar } \\
\text { na agenda política, assumir o poder deliberativo em alguns } \\
\text { planos e programas e alterar os serviços desenvolvidos. Os } \\
\text { cidadãos possuem a maior influência no processo de decisão e } \\
\text { irão julgar questões que eles ajudaram a formular. }\end{array}$ & \\
\hline
\end{tabular}




\begin{tabular}{|c|l|l|}
\hline $\begin{array}{c}\text { Propriedade } \\
\text { conjunta }\end{array}$ & $\begin{array}{l}\text { A característica principal nesse nível de participação é a relação } \\
\text { indissociável entre representantes e representados, os } \\
\text { cidadãos realizam uma autogestão. }\end{array}$ & \\
\hline
\end{tabular}

Fonte: elaborado com base em Damgaard e Lewis, 2014.

O conteúdo do quadro 1 esclarece que, na não participação, os cidadãos são apenas informados sobre as decisões realizadas, sem a possibilidade de questionar. São dados que podem ser manipulados para gerar um cenário mais positivo do governo ou da instituição, ou seja, podem produzir a desinformação. Pretty et al. (2005) denomina este nível de 'Participação Passiva'. Essa não participação destacada pelas autoras pelo nível 'Educação', assemelha-se muito ao modelo de comunicação de mão única, descritos por Grunig (2009a), no qual existe uma preocupação das instituições em apenas divulgar as informações positivas, estimulando uma linguagem persuasiva, no intuito de convencer os seus públicos, sem disponibilizar espaço para diálogo e questionamentos. A participação simbólica estabelecida pelo nível 'Envolvimento' esclarece que os cidadãos são informados e podem até questionar sobre assuntos preestabelecidos, mas não possuem influência no processo decisório. As decisões são tomadas e a sociedade é apenas informada sobre o que já foi definido. Pretty et al. (2005) denomina este nível como 'Participação na Informação Dada' e 'Participação por Consulta'.

Os conceitos de não participação e de participação simbólica são similares ao conceito apresentado de accountability, visando à transparência, à responsabilidade, à prestação de contas, ao controle, à fiscalização, à justificativa e à sanção (O'DONNEL, 1998; SCHEDLER, 1999; MAINWARING, 2003; PINHO; SACRAMENTO, 2009). As instituições públicas divulgam as mensagens, mas não existe uma preocupação se essas informações são relevantes para o cidadão, além disso, não incitam o debate, nem verificam as necessidades informacionais da sociedade.

O poder cidadão é a última forma de participação; esse tipo de participação está presente nos níveis: 'Conselho', 'Colaboração' e 'Propriedade Conjunta', esses são os níveis mais elevados de participação. Nesse momento, predomina-se efetivamente a accountability, que convida os atores sociais a se envolverem de forma ativa no processo decisório e, também, no controle e na fiscalização das ações (PERUZZOTTI; SMULOVITZ, 2002)

Iniciando com o terceiro nível de participação, 'Conselho', o cidadão é orientado a questionar, a expressar sua opinião e a julgar assuntos pautados pelo Estado. O que diferencia o nível 'Colaboração' do nível apresentado anteriormente é o fato de o cidadão influenciar na agenda política e a possibilidade de poder alterar os serviços ofertados. O que Damgaard e Lewis (2014) 
denomina de colaboração na tipologia de Pretty et al. (2005) e conhecido como 'Participação Interativa'.

No quinto nível de participação, 'Propriedade conjunta', o cidadão possui um papel gerencial completo. As autoras Damgaard e Lewis (2014) destacam que mesmo que níveis mais elevados de participação estejam em ascensão, exemplos demonstrando o nível 'Propriedade Conjunta' não existem ou raramente são encontrados. Pretty et al. (2005) denomina este tipo de participação de 'automobilização'.

A forma de participação 'Poder cidadão' está alinhada com o modelo de comunicação de duas mãos apresentado por Grunig (2009a). O autor salienta a preocupação das instituições em escutar os seus públicos, prestar contas, possibilitar o diálogo e realizar a abertura para negociações e concessões.

É importante destacar que existe uma relação de codependência entre os tipos e formas de participação e a comunicação pública, pois, no intuito de estabelecer uma comunicação simétrica entre o Estado e a sociedade, a comunicação pública baseia-se na informação, na consulta, na deliberação, na negociação e no compromisso (LÓPEZ, 2004).

\section{MÉTODOS E TÉCNICAS DE PESQUISA}

Este trabalho foi construído sob a égide do pressuposto filosófico pós-positivista. O termo pós-positivismo é trazido por Creswell (2014) como uma maneira de relaxar determinadas crenças absolutistas do positivismo clássico. Estudos qualitativos construídos sobre este paradigma empregam lentes teóricas a priori, não são estritos na busca de explicações de fenômenos por meio de relações causais, se estruturam em uma série de passos que estão relacionados logicamente, se pautam na possibilidade de realidades múltiplas, e se orientam por métodos rigorosos de coleta e análise de dados (CRESWELL, 2014). Estes elementos e crenças estão presentes na construção desta pesquisa.

O método de pesquisa configura-se como qualitativo. Tal abordagem possui diversas formas de definição, porém, de maneira geral, ela pode ser apreendida como um meio de compreender as relações sociais e/ou humanas. Os pesquisadores adeptos a este método realizam seus estudos dentro do contexto natural em que eles ocorrem, buscam entender os fenômenos existentes (CRESWELL, 2014) e examinam as interações e comunicações desenvolvidas no contexto social pesquisado (ANTUNES; OCTAVIO NETO; VIEIRA, 2016). 
O objetivo geral estabelecido para o artigo demanda uma aproximação com a pesquisa do tipo descritiva uma vez que o estudo se propõe a descrever se, e, de que forma os governos locais vem se utilizando da mídia social Facebook para a promoção de accountability e participação social. Há assim explicitamente, na construção da narrativa do objetivo do estudo, uma intenção de descrever o fenômeno, característica central destes tipos de estudos segundo Triviños (1987).

Como estratégia de pesquisa optou-se pela pesquisa de campo virtual. A pesquisa de campo é uma denominação atribuída a estudos que são materializadas no ambiente natural dos sujeitos, onde eles são observados, de forma não controlada, pelo pesquisador, que o faz de maneira não participante (GODOY, 1995). A pesquisa de campo virtual está sendo entendida como uma apropriação da definição de pesquisa de campo clássica de Godoy (1995) e, tomando o devido cuidado metodológico, adaptando-a aos projetos cujo o corpo empírico está situado no ciberespaço, onde, contemporaneamente, parece ser um habitat natural aos humanos, porém virtual.

Após evidenciar a orientação filosófica que guiou a pesquisa, o tipo de pesquisa, a utilização do método e a estratégia de pesquisa, a seguir serão apresentados o objeto de estudo desta pesquisa - os Facebook dos governos locais e discutidas as técnicas de coleta e análise de dados para a busca do cumprimento do objetivo geral do estudo.

\subsection{Mídias Sociais Pesquisadas: a escolha dos Facebook}

Por se tratar de uma pesquisa com características qualitativas, onde não se persegue padrões de comportamentos, determinismo e capacidade inferencial dos resultados, não houve qualquer prática ou preocupação de se constituir uma amostra com os rigores estatísticos. Pesquisas qualitativas buscam a diversidade, tem caráter subjetivo e seus sujeitos ou objetos de pesquisa são escolhidos intencionalmente. Dentro deste cenário optou-se por trazer para a análise empírica o Facebook de uma capital de cada região geográfica do Brasil. O critério de inclusão estabelecido foi, simplesmente, que a mídia governamental estivesse ativa e demonstrasse estar passando por atualizações diariamente. As cidades escolhidas, então, foram Porto Alegre, Belo Horizonte, Goiânia, Fortaleza e Porto Velho. Com intenção apenas informativa, algumas características das mídias sociais destas gestões municipais podem ser verificadas no quadro 2

Quadro 2 - Características das mídias sociais das gestões dos municípios pesquisados.

\begin{tabular}{|c|c|c|c|c|}
\hline Cidade & $\begin{array}{c}\text { Data de } \\
\text { Criação }\end{array}$ & $\begin{array}{c}\text { Número de } \\
\text { Seguidores }\end{array}$ & $\begin{array}{c}\text { Número de } \\
\text { Curtidas }\end{array}$ & Médias de Postagens Diárias \\
\hline Porto Alegre & $01 / 10 / 2010$ & 126.886 & 110.672 & 3 \\
\hline
\end{tabular}




\begin{tabular}{|l|c|c|c|c|}
\hline Belo Horizonte & $15 / 02 / 2011$ & 255.076 & 231.517 & 2 \\
\hline Goiânia & $25 / 02 / 2013$ & 95.374 & 81.750 & 4 \\
\hline Porto Velho & $08 / 05 / 2012$ & 50.724 & 50.214 & 3 \\
\hline Fortaleza & $19 / 04 / 2011$ & 258.988 & 238.527 & 4 \\
\hline
\end{tabular}

Fonte: Facebook das Prefeituras (atualizado em 20/06/2019) .

\subsection{Técnicas e instrumentos de coleta dados empregados na análise do Facebook das Gestões Municipais}

O primeiro passo que se fez necessário para acessar o Facebook das cidades pesquisadas foi criar, em nome de um dos pesquisadores, um perfil no na rede social, para que por meio deste, se pudesse entrar em campo para a execução do processo de observação. Em seguida, escolheu-se a janela de tempo de observação que os pesquisadores iriam permanecer imersos no processo de coleta de dados. Entendeu-se, por experiências anteriores em pesquisas em ambientes virtuais, e em função de uma pesquisa exploratória antecedente, realizada nas mídias sociais escolhidas para o estudo, que noventa dias seria uma janela suficiente para a coleta de dados. Assim ficou estabelecido o intervalo entre 12/03/2019 a 12/06/2019. Durante esta janela temporal, os pesquisadores acessavam os Facebook das prefeituras sem a preocupação de uma sistematização periódica para acessos, pois os posts realizados ficam armazenados na linha de tempo das mídias sociais das prefeituras. Desta forma, foi possível promover as devidas recolhas de dados em datas retroativas às da data efetiva em que se estava sendo realizadas as observações virtuais.

Foi considerado e analisado, durante o processo de observação, todo o material disponibilizado em texto, imagem, vídeo e áudio. Porém, vale pontuar que são de interesse, para este estudo, somente os dados que se referem à accountability com participação, de acordo com as dimensões e as categorias desenvolvidas, apresentadas em tópico específico neste capítulo.

Este processo demandou a construção de um banco de dados de posts das prefeituras, no decorrer da pesquisa, no qual se extraía, em um primeiro momento, todas as informações dos Facebook. Posteriormente eram excluídos os posts que não se enquadravam nas unidades de análise do estudo. Para num momento final, ocasião da análise propriamente dita, promover a categorização dos posts.

Nesta fase de coleta de dados foi utilizada a observação não participante on-line, por ser o Facebook uma plataforma digital e devido ao cenário de comunicação on-line. A estratégia é caracterizada como observação simples, pois permite ao pesquisador atuar como espectador, não exercendo nenhuma atividade direta no contexto analisado (SANTOS; COSTA, 2015). É sabido que a 
aplicação de uma observação rigorosa e organizada poderá atribuir confiabilidade e validade ao estudo (MARTINS, 2006).

Após a coleta das informações nas fanpages dos governos locais, foi realizada uma análise de conteúdo para sistematizar e buscar compreender os dados levantados. A análise de conteúdo foi utilizada nesta pesquisa por ser um instrumento metodológico em eterno aprimoramento, que pode ser empregada em diversos tipos de discursos produzidos em textos, imagens e sons, sendo definida de forma resumida como:

Um conjunto de técnicas de análise das comunicações visando obter por procedimentos sistemáticos e objetivos de descrição do conteúdo das mensagens indicadores (quantitativos ou não) que permitam a inferência de conhecimentos relativos às condições de produção/recepção (variáveis inferidas) destas mensagens (BARDIN, 2013, p. 44).

Ressalta, mais uma vez, que nesta pesquisa os dados foram tratados de forma qualitativa, baseando-se na presença ou na ausência de traços de accountability e participação social, bem como dos tipos de práticas de comunicação realizados nos conteúdos postados nos Facebook pesquisados. Simultaneamente, foi realizada uma análise de conteúdo para identificar, também, as estratégias de comunicação adotada pelas prefeituras no Facebook. Para a compreensão desse fenômeno, foram utilizados os dois modelos de relações públicas de comunicação propostos por Grunig (2009a).

\subsection{Desenvolvimento e Apresentação das Categorias de Análise}

Com o objetivo de analisar os conteúdos postados no Facebook das prefeituras, foram desenvolvidas dimensões e categorias de análise cujas finalidades foram estabelecer parâmetros para identificar se essa mídia social é utilizada pelas instituições como espaço para promover práticas de accountability com participação, além de verificar os processos e as práticas de comunicação pública, destacando os modelos de comunicação praticados por essas instituições. As dimensões e categorias de análise foram criadas a partir do referencial teórico discutido para a presente pesquisa.

De acordo com Bardin (2013), o processo de categorização é um dos procedimentos mais comumente praticado quando realizada a análise de conteúdo. Para a autora, categorização é:

uma operação de classificação de elementos constitutivos de um conjunto por diferenciação e, seguidamente, por reagrupamento segundo o gênero (analogia), com os critérios previamente definidos. As categorias são rubricas ou classes, as quais reúnem um grupo de elementos (unidades de registro, no caso da análise de conteúdo) sob um título genérico, agrupamento esse efetuado em razão das características comuns desses elementos (BARDIN, 2013, p. 145). 
Cabe ressaltar, também, que o método das categorias empregado neste estudo recorreu ao procedimento de "caixas" ou "gavetas", no qual as dimensões e categorias foram inicialmente criadas e, posteriormente, os posts foram classificados e colocados dentro das respectivas gavetas fazendo surgir uma nova ordem e sentido aos dados iniciais (BARDIN, 2013).

As categorias desenvolvidas foram baseadas nos níveis de participação cidadã na accountability propostos por Damgaard e Lewis (2014), nos quais estabelecem os cinco níveis de participação: educação, envolvimento, conselho, colaboração e propriedade conjunta. Esse framework estabelecido pelas autoras é uma adaptação da escada de participação cidadã proposta por Arnstein (1969).

Ao examinar mais detalhadamente os níveis de accountability com participação estabelecidas por Damgaard e Lewis (2014), foi possível perceber que os dois primeiros níveis de participação: educação e envolvimento, considerados pelas autoras como formas de não participação e participação simbólica "tokenism", respectivamente, vão ao encontro do conceito de transparência desenvolvido pelos autores Pinho e Sacramento (2009) e Platt Neto et al. (2007). Devido a esta constatação, os níveis de accountability com participação foram segmentados em duas dimensões: transparência e participação. Bardin (2013) destaca que na análise de conteúdo pode ser necessária a divisão das categorias em uma ou várias dimensões de análise, o que permite o agrupamento de mensagens que possuem similaridades.

Realizada a criação das duas dimensões destacadas, foi possível perceber que a dimensão transparência, composta pelas categorias: informação e envolvimento estão diretamente vinculada aos modelos de comunicação assimétrica e de mão única (GRUNIG, 2009a). Em contrapartida, a dimensão participação, composta pelas categorias: parceria, colaboração e propriedade conjunta, demanda um modelo de comunicação simétrica e de mão dupla também estabelecido por Gruning (2009a).

Destaca-se que as tipologias de participação desenvolvidas por Pretty et al. (1995) também foram importantes na elaboração das categorias, uma vez que os tipos de participação desempenhados pelo cidadão no processo decisório, em sua proposição, assemelham-se bastante aos níveis de accountability com participação estabelecido por Damgaard e Lewis (2014).

Desse modo, a significação e os parâmetros de cada categoria de análise foram construídos considerando o referencial teórico deste estudo, tendo como embasamento os autores: Damgaard e Lewis (2014); Arnstein (1969); Pinho e Sacramento (2009); Platt Neto et al. (2007); Grunig (2009a); 
Pretty et al. (1995). No quadro 3 consta apresentação detalhada das dimensões e das categorias de análise estabelecidas.

Quadro 3 - Categorias de análise da accountability com participação.

\begin{tabular}{|c|c|c|c|c|}
\hline $\begin{array}{l}\text { Dimensões de } \\
\text { Accountability }\end{array}$ & $\begin{array}{l}\text { Categorias de } \\
\text { análise da } \\
\text { Accountability }\end{array}$ & $\begin{array}{l}\text { Características de } \\
\text { significação }\end{array}$ & Referencial & Parâmetros de análise \\
\hline \multirow[t]{2}{*}{ Transparência } & Informação & 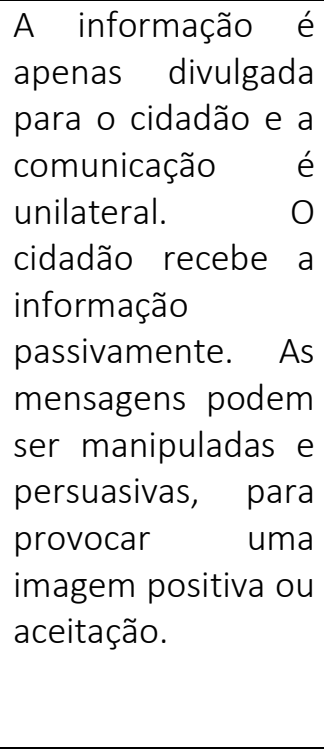 & $\begin{array}{l}\text { Arnstein } \\
\text { (1969); } \\
\text { Damgaar e; } \\
\text { Lewis } \\
\text { (2014); } \\
\text { Pretty et al. } \\
\text { (1995); } \\
\text { Grunig } \\
\text { (2009a); } \\
\text { Pinho; } \\
\text { Sacrament } \\
\text { o (2009); e } \\
\text { Platt Neto } \\
\text { et al. } \\
\text { (2007). }\end{array}$ & $\begin{array}{l}\text { Postagens promovidas } \\
\text { pelas prefeituras de } \\
\text { caráter institucional, } \\
\text { gestão, utilidade pública, } \\
\text { interesse privado, } \\
\text { mercadológico, prestação } \\
\text { de contas e dados públicos. } \\
\text { Não existe a intenção de } \\
\text { encorajar a participação do } \\
\text { público. Posts que } \\
\text { intencionam comunicar o } \\
\text { que aconteceu ou o que iráa } \\
\text { acontecer em termos de } \\
\text { ações ou decisões. } \\
\text { Comunicação assimétrica } \\
\text { de mão única. }\end{array}$ \\
\hline & Envolvimento & 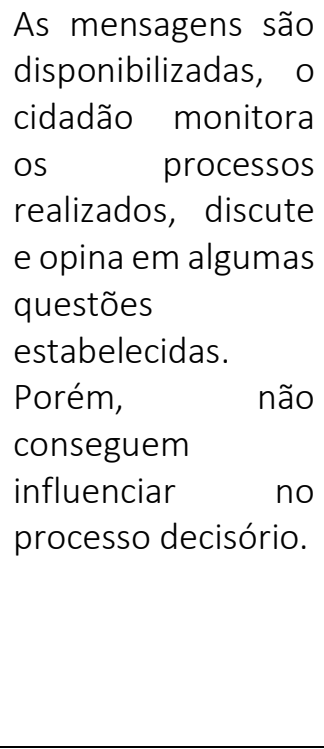 & $\begin{array}{l}\text { Arnstein } \\
\text { (1969); } \\
\text { Damgaard } \\
\text { e Lewis } \\
\text { (2014); } \\
\text { Pretty et al. } \\
\text { (1995); } \\
\text { Grunig } \\
\text { (2009a); } \\
\text { Pinho e } \\
\text { Sacrament } \\
\text { o (2009); e } \\
\text { Platt Neto } \\
\text { et al. } \\
\text { (2007). }\end{array}$ & $\begin{array}{l}\text { Postagens promovidas } \\
\text { pelas prefeituras de } \\
\text { caráter institucional, } \\
\text { gestão, utilidade pública, } \\
\text { interesse privado, } \\
\text { mercadológico, prestação } \\
\text { de contas e dados públicos. } \\
\text { Não existe a intenção de } \\
\text { provocar/encorajar ar a } \\
\text { participação do público. } \\
\text { Posts que intencionam } \\
\text { comunicar o que } \\
\text { aconteceu ou o que irá } \\
\text { acontecer em termos de } \\
\text { ações ou decisões } \\
\text { realizadas. Comunicação }\end{array}$ \\
\hline Participação & Parceria & $\begin{array}{l}\text { Existência de tipos } \\
\text { mais formais de } \\
\text { influência do } \\
\text { cidadão, que coloca } \\
\text { assuntos em pauta } \\
\text { para a discussão e }\end{array}$ & $\begin{array}{l}\text { Arnstein } \\
\text { (1969); } \\
\text { Damgaard } \\
\text { e Lewis } \\
\text { (2014); } \\
\text { Grunig, } \\
\text { (2009a). }\end{array}$ & $\begin{array}{l}\text { Postagens nas quais as } \\
\text { prefeituras instam os } \\
\text { usuários a analisar e a } \\
\text { julgar suas ações e } \\
\text { desempenho pretéritos. } \\
\text { Dispõe a promover mais } \\
\text { informações sobre o tema }\end{array}$ \\
\hline
\end{tabular}




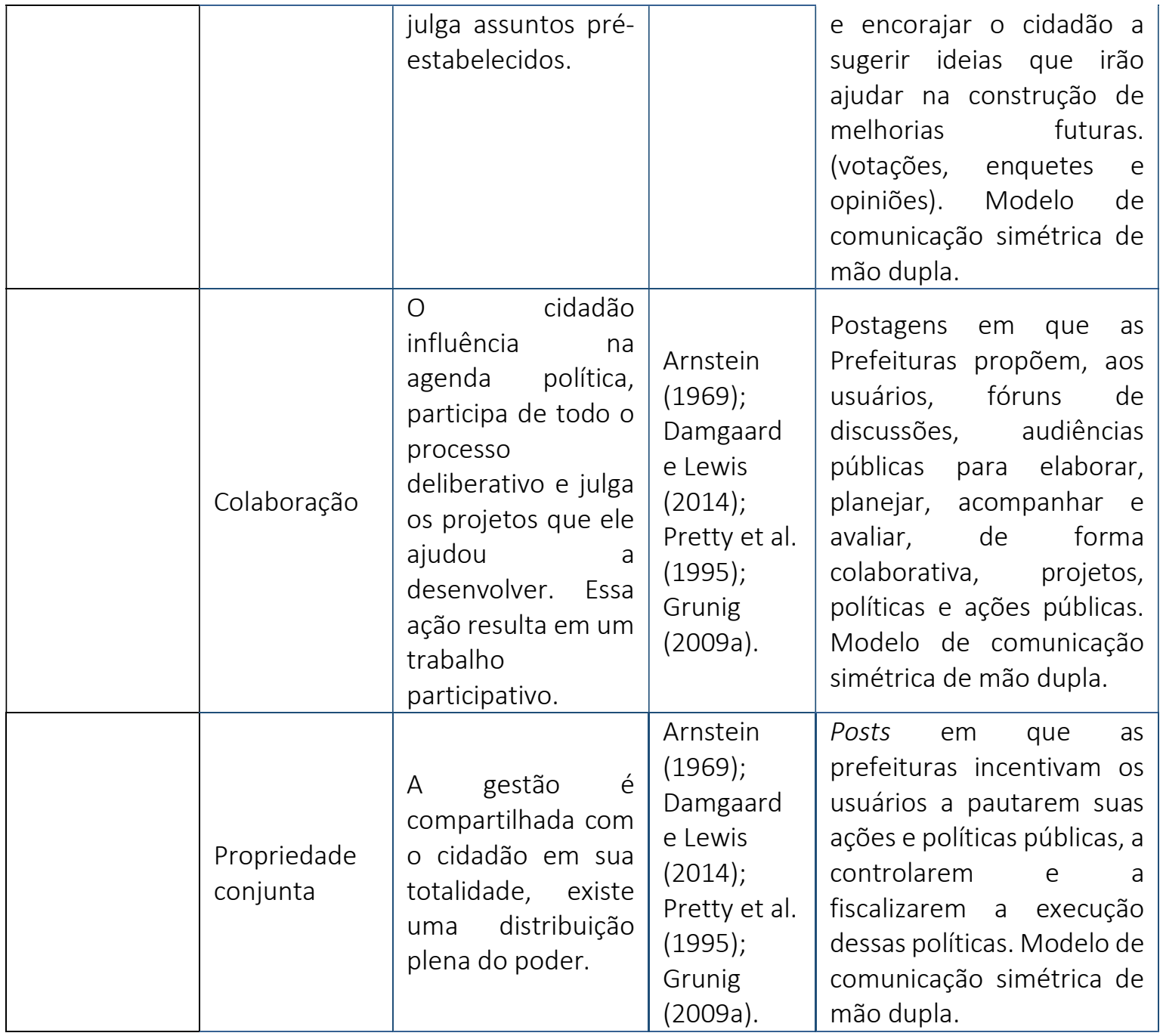

Fonte: elaboração com base nos autores mencionados.

\section{ANÁLISE E DISCUSSÃO DOS DADOS}

A análise dos posts das prefeituras foi realizada por categorias, portanto, a apresentação e a discussão dos resultados iniciarão pela dimensão transparência, começando com as categorias 'informação e envolvimento' e, posteriormente, pela dimensão participação, com as categorias 'parceria, colaboração e propriedade conjunta', respectivamente. Por questões puramente de economicidade de espaço não será trazido para a discussão dos resultados os posts que constituíram os achados de cada categoria. No entanto, como já informando anteriormente, os referidos posts constam em banco de dados construído para este fim.

\section{Categoria 'Informação'}

A categoria 'informação' foi encontrada em todas as páginas do Facebook dos governos locais pesquisados. fortemente presente na maioria dos posts realizados pelas instituições. Assim, é 
razoável inferir, em um primeiro momento, que a comunicação pública realizada nas instituições por meio do Facebook está predominantemente ancorada na divulgação das informações.

Em análise dos conteúdos postados na timeline dos governos pesquisados, verificou-se que os eventos informativos se classificam nos mais diversos assuntos dentro da classificação de Duarte (2007). Entretanto, os tipos de informação que mais se destacaram foram as informações: Institucionais - informes ligados à projeção da imagem e à consolidação da identidade da gestão; De Gestão - comunicados relativos ao processo decisório e de ação dos agentes que atuam em temas de interesse público; e Mercadológicas - aquelas referentes a assuntos de fornecimento de produtos e serviços que são oferecidos pelo governo. Em menor incidência foram encontradas as informações de: Utilidade Pública - conteúdos que procuram informar, mobilizar, prevenir ou alertar a população ou setores específicos dela para temas de seu interesse; Dados Públicos - informes de controle do Estado e que dizem respeito ao conjunto da sociedade e a seu funcionamento; Prestação de Contas - conteúdos que explicam as decisões políticas e uso de recursos públicos, viabilizando o conhecimento, a avaliação e a fiscalização; e Interesse Privado - informes dirigidos exclusivamente ao cidadão, empresa ou instituição.

As informações institucionais, de gestão e mercadológicas são apresentadas no Facebook das prefeituras de forma insistente, principalmente por meio de vídeos e demonstram a realização de obras, tais como: praças, creches, escolas, iluminação e tapa buracos, ficando explícito nesses posts os progressos realizados, destacando uma imagem sempre positiva da gestão dos governos locais. Entretanto, nesses vídeos são expressos apenas os benefícios que tais obras e projetos irão oferecer a sociedade. Não são expostos os valores gastos nas obras, a fonte dos recursos ou o cronograma das obras, dentre outros informes, com fins de prestar contas para o cidadão. Essa situação pode ser verificada em todas as prefeituras, mas principalmente na prefeitura de Fortaleza, no qual esses conteúdos são realizados no Facebook como se o próprio gestor escrevesse as postagens, uma vez que elas estão redigidas entre aspas, na primeira pessoa do singular e ao final tem o nome do prefeito entre parênteses.

A prefeitura de Belo Horizonte realiza postagens vinculadas somente à categoria 'informação'. Não foram encontrados posts realizados por essa instituição no Facebook que pudessem ser classificados em outras categorias.

Esse cenário permite considerar que a comunicação pública nas prefeituras ainda está fortemente relacionada à visibilidade, com um viés publicitário, uma linguagem persuasiva que visa criar uma imagem positiva de um gestor (DUARTE, 2007), demonstrando as obras e projetos da 
gestão de forma positiva e massiva. Tal comportamento comunicacional das administrações locais, no Facebook, pode ser enquadrada em uma pratica de comunicação assimétrica e de mão única conforme classificação de Grunig (2009a).

A publicidade garante à sociedade o direito de saber acerca dos atos praticados pela instituição (ALLEGRETTI; PLAAT NETO, 2010). As prefeituras utilizam o Facebook com esse intuito ao informar e dar transparência às suas ações, sendo esse o fator primário no processo de comunicação pública (LÓPEZ, 2004). Todavia, enquanto crítica, entende-se que as instituições poderiam extrapolar o âmbito da divulgação das informações e utilizar o Facebook como ferramenta para fortalecer o relacionamento com os cidadãos e incitar a participação. A utilização das redes sociais de maneira eficiente, de acordo com Grunig (2009b), pode auxiliar as instituições a promover uma comunicação simétrica e de mão dupla.

\section{Categoria 'Envolvimento'}

Analisando-se, ainda, a dimensão transparência, porém na categoria 'envolvimento', foi verificado que as prefeituras analisadas, com exceção feita a Belo Horizonte, possuem conteúdos postados no Facebook que podem ser classificados nesse tipo. Contudo, com uma quantidade de posts inferior em relação à categoria 'informação' analisada anteriormente.

As prefeituras realizam postagens de conteúdos que solicitam a apreciação, o monitoramento e a opinião dos cidadãos. Entretanto, não é encontrado por parte do gestor local, o compromisso em aceitar ou considerar as contribuições realizadas pelos usuários, proporcionando o que Arnstein (1969) classifica como 'tokenism' ou participação simbólica.

As prefeituras de Porto Alegre e de Porto Velho, destacam-se por postar conteúdos que incitam esse nível de accountability com participação. As instituições, em seus posts, buscam sugestões, opiniões e contribuições, mas todas as ações e decisões já foram realizadas pela administração e nada poderá ser modificado, independentemente da opinião dos usuários. Não há indicativo nos posts de que essas solicitações resultarão em melhorias futuras. Essa forma de comunicação acarreta uma sensação de pertencimento e de aproximação com a sociedade, todavia pode gerar também uma frustração por parte do cidadão que participa, por não ter suas ideias consideradas ou um feedback do motivo da não aceitação de sua sugestão. Essa situação pode gerar uma redução na participação, conforme destacado por Nascimento (2014).

O 'envolvimento', por mais que incite a participação simbólica e estreite a comunicação, ainda é uma estratégia comunicacional de mão única e assimétrica (GRUNIG, 2009a), visto que os governos locais ainda estão realizando uma comunicação vertical com a sociedade. 
A dimensão transparência aparece fortemente nesta pesquisa, uma vez que foram encontrados números expressivos de posts, no Facebook de todas as prefeituras pesquisadas, que podem ser classificados nas categorias informação e envolvimento. As prefeituras possuem uma estratégia de comunicação pautada na divulgação de informações e praticam um modelo assimétrico de comunicação entre emissor e receptor, no qual os interesses das instituições/gestores acabam prevalecendo em detrimento dos interesses dos seus públicos. Contudo, o que se aspira, em sociedades com democracias maduras é que, gradativamente, debates e ações possam ser conduzidos na tentativa de modificar esse cenário, a fim de direcionar a comunicação pública para os interesses da sociedade (DUARTE, 2007). Essa situação pode ser verificada neste estudo, que encontrou, ainda que de forma reduzida, conteúdos postados pelas administrações locais que se enquadram na dimensão participação, ou seja, que envolvem o cidadão no processo decisório, prevalecendo nos projetos e nas políticas as opiniões da sociedade, ainda que essa interação não seja realizada no Facebook, e sim em outras plataformas ou de forma presencial.

\section{Categoria 'Parceria'}

Após ultrapassar as abordagens unicamente informativas foi possível identificar em uma única prefeitura que, além de incitar a opinião dos usuários, considera suas sugestões para melhorias futuras. Nesse estágio, inicia-se efetivamente a accountability com participação em assuntos prédeterminados e pretéritos de acordo com os níveis de participação proposto por Damgaard e Lewis (2014), Arnstein (1969) e Pretty et al. (1995). A categoria parceria foi encontrada em apenas dois posts, ambos realizados pela prefeitura de Porto Alegre. O primeiro post foi realizando no dia 2 de abril de 2019 e a prefeitura solicitou a ajuda dos moradores para destacarem quais projetos seriam mais importantes em um determinado bairro. Para obter esse auxílio, a prefeitura entrevistou e verificou a opinião de 143 moradores do bairro. A segunda postagem, datada de 6 de junho de 2019, realizou uma consulta pública com a sociedade por meio de um questionário sobre o transporte compartilhado implementado pela prefeitura.

É muito importante ressaltar que esses conteúdos postados pela prefeitura de Porto Alegre solicitando a participação do cidadão não oportunizava que essa participação acontecesse no próprio Facebook. As sugestões e opiniões foram sempre obtidas de forma presencial ou os usuários da mídia social eram direcionados para outra plataforma ou aplicativo específico para consulta ou avaliação de determinado tema. De certa forma, esse fato se contrapõe ao objetivo estabelecido para esta pesquisa, pois a ideia central é constatar o uso da rede social para promover a accountability com participação. Dessa maneira, apesar de evidenciados traços de participação por parte das prefeituras estudadas, esse fenômeno está sendo construído fora da mídia social. O 
Facebook é utilizado simplesmente para informar ou convidar a sociedade a participar da gestão fora da plataforma.

A prefeitura de Porto Alegre ao realizar postagens no Facebook que podem ser classificadas nessa categoria está adotando uma comunicação simétrica de duas mãos (GRUNIG, 2009a), a qual demonstra interesse em ouvir os cidadãos e abre espaço para o diálogo, para a consulta, para a deliberação, para a negociação e para o compromisso (LÓPEZ, 2004). É reconhecida nesse contexto uma mudança de comportamento da prefeitura em convidar a sociedade a participar, extrapolando a postura de apenas divulgar as informações, garantindo que a sociedade seja ouvida e gerando um espaço mais democrático. Entretanto, pelo fato de a parceria estar acontecendo fora da rede social, a prefeitura ainda está apenas convidando e incitando a participação, fato caracterizado por Grunig (2009a) como modelos assimétricos de comunicação.

Destaca-se, neste ponto, que o Facebook possui várias funcionalidades, que possibilitariam às prefeituras obterem as opiniões dos usuários na própria rede social, seja por meio dos comentários, de enquetes ou de pesquisas on-line. No limite, pode-se concluir que a gestão municipal não conseguiu, ainda, se dar conta das funcionalidades do Facebook para a promoção da accountability com participação.

\section{Categoria 'Colaboração'}

Categoria da dimensão participação, insta a sociedade a participar de discussões no intuito de produzir, acompanhar e avaliar projetos e políticas públicas de maneira conjunta. O grande diferencial entre a 'colaboração' e a 'parceria' é a inclusão da sociedade. O cidadão participa não apenas na identificação de melhorias e fornece sugestões, mas também na construção de todo o processo (planejar, elaborar, avaliar, monitorar) de políticas públicas ou projetos. A sociedade consegue, dessa maneira, alterar a agenda pública e modificar os serviços desenvolvidos.

Foi encontrado apenas um post, realizado pela prefeitura de Goiânia, que poderia ser classificado na categoria 'colaboração'. A prefeitura realizou uma postagem no dia 12 de março de 2019 convidando a sociedade para participar da 10a Conferência Mundial de Saúde de Goiânia, visando sugerir e debater propostas para a melhoria e o desenvolvimento de políticas públicas do Sistema Único de Saúde da cidade. Porém, a exemplo do que se constatou na categoria parceria, a discussão proposta pela gestão da cidade não ocorreu no Facebook. Os usuários foram convidados a participar de maneira presencial em uma conferência, o que causa uma subutilização da ferramenta e reduz a utilização do canal de comunicação para um papel meramente informativo. Este post pode demonstrar a intenção de encorajar a accountability com participação na prefeitura, 
todavia esse processo está ocorrendo alheio à mídia social objeto deste estudo. Ratifica-se que no Facebook podem ser criados, por exemplo, grupos de discussões ou fóruns para que tais eventos possam ocorrer de forma mais otimizada.

Um dos motivos levantados por Lavalle e Vera (2011) que pode explicar as dificuldades de participação direta do cidadão nas democracias contemporâneas é o tamanho territorial e populacional do Estado. Neste estudo, vislumbra-se que o ambiente digital possa ser uma alternativa para que essa dinâmica de tempo e espaço seja fisicamente reduzida, o que possibilitaria à sociedade discutir de forma direta assuntos por meio do Facebook, sem a necessidade de se fazer presente em determinado momento e local para tal discussão. Este fenômeno é tido como um dos affordances que as mídias sociais podem ofertar para o processo de accountability com participação, mas que as gestões municipais pesquisadas parecem não ter atentado para esta vantagem.

Este único post não permite inferir que esteja havendo um processo de reinstitucionalização da comunicação das gestões estudadas, fundamentada no intuito de trabalhar uma comunicação horizontal com a sociedade. A comunicação nesse estágio deveria ser pautada pelo modelo simétrico de duas mãos (GRUNIG, 2009a), pois nesse momento, além da prefeitura prestar contas e convocar o público para o diálogo, ela possibilitaria também a abertura de um espaço para negociações e concessões, promovendo um equilíbrio maior entre os interesses da instituição e da sociedade.

\section{Categoria 'Propriedade Conjunta'}

Esse é o nível de accountability participativa mais elevado, no qual a instituição deveria incentivar a sociedade a pautar suas políticas e projetos. Seriam ações planejadas, executadas e monitoradas pela sociedade. Nesse estágio, existe um compartilhamento igualitário do poder e não há desigualdades entre os agentes nessa relação.

Conforme já destacado pelas autoras Damgaard e Lewis (2014) a 'propriedade conjunta' é um nível de accountability participativa raramente encontrada ou inexistente. Essa situação foi confirmada nesta pesquisa, uma vez que não foram identificados conteúdos nas fanpages das prefeituras pesquisadas que tivessem traços dessa categoria. Considera-se, portanto, uma categoria sem evidências empíricas ou uma categoria teórica vazia.

\section{CONCLUSÕES}

A sociedade moderna tem vivido dois "mundos" paralelos: o tradicional, real, factual, que empreende uma dinâmica de tempo e espaço e um processo de relacionamento mais pessoalizado; 
e, um outro, virtual, imaterial, onde as relações humanas se dão no ciberespaço e que impõe uma dinâmica de tempo e espaço diferentes ao do mundo real. Independentemente de como se posicionar em relação a este mundo paralelo, negá-lo seria negar a realidade vigente. Os pesquisadores, de várias filiações epistemológicas e variados campos de estudo, demonstram reconhecer este mundo virtual como um terreno cada vez mais fértil para o desenvolvimento de suas pesquisas. Destaque é dado às Ciências Sociais que vem empreendendo esforços para entender e explicar como as relações entre pessoas, instituições, máquinas e tecnologias estão se dando nas nuvens. Esta pesquisa se reconhece nesta lacuna, entender como os governos locais se utilizam de ferramentas virtuais para promover melhorias em seu processo de comunicação com a sociedade e com isto, a busca de uma substantivação do processo democrático.

Ao propor este trabalho, cuja intenção tácita foi verificar se as organizações públicas estão subvertendo as finalidades originais para qual o Facebook foi criado, se faz porque se vislumbra que esta ferramenta tem potencial de produzir contribuições tanto para a gestão local quanto para a sociedade. As mídias sociais, quando utilizadas para a promoção de accountability com participação poderia contribuir com a administração pública ao promover: mais transparência, maior demonstração de responsabilização, caráter mais participativo, uma gestão inovadora, maior legitimidade, maior credibilidade e internamente uma reinstitucionalização da comunicação governamental. Por outro lado, benefícios podem ser trazidos para a sociedade, tais como: conscientização do público, maior percepção democrática, sentimento de empoderamento, melhoria da qualidade de vida, maior confiança na gestão pública, engajamento e identidade com a coisa pública.

Apesar de apontada essa diversidade de contribuições que a comunicação nas redes sociais pode trazer para ambos (governo e sociedade), os achados, de maneira geral, apontam para um não despertar dos gestores locais quanto as essas possibilidades. Os resultados empíricos indicam haver uma subutilização da mídia social Facebook para promover a accountability com participação. As prefeituras estão se limitando a promover, de forma restrita, a transparência das suas ações, ao transformar a rede social em um mero instrumento de informação.

É importante salientar que devido ao fato das postagens das prefeituras serem predominantemente informacionais institucionais, de gestão e mercadológica, essa comunicação pode gerar uma desinformação ao cidadão, uma vez que existe uma preocupação extrema de praticamente todas as prefeituras em transmitir apenas uma imagem positiva da gestão, utilizando a rede social como forma de promoção do atual governo, deixando de realizar uma comunicação eficiente com o cidadão. 
Em termos de envolvimento, categoria presente em menor quantidade do que a categoria informação, o que se pode aduzir é que as gestões locais se utilizaram desse tipo de forma retórica. Consultas, questionamentos e disponibilização de temas para apreciação sem, contudo, assumir o compromisso com medidas de melhorias futuras na prestação de serviços ou oferecimentos de políticas públicas. Ainda sobre resultados na dimensão transparência, o que se percebe, do conteúdo analisado, é que os tipos de informação prestada pelas gestões estudadas são minimamente institucionalizados em termos de prestação de contas, transparência e responsabilização da gestão. Em muitos momentos, os gestores ao apresentarem a entrega ou as etapas dos projetos municipais, o fazem de uma maneira muito pessoal, e não disponibilizam à sociedade os dados sobre tais políticas públicas que pudessem fornecer ao cidadão a possibilidade de colocar em discussão temas relacionados aos feitos.

Em análise a dimensão participação, não obstante ser este um estudo qualitativo, mas considerando a quantidade de fanpages analisadas, a janela de tempo utilizada na pesquisa e a quantidade de posts que emergiram enquanto dados, encontrar três postagens que podem ser qualificadas na categoria participativa, parece ser próximo do inexistente. Além disso, para essas três postagens, especificamente, os cidadãos foram convidados para participar do processo de decisões administrativo/político em ambientes externos ao da rede social, que de certo modo se contrapõe ao objetivo deste estudo que é verificar se existe accountability com participação no Facebook. Isto conduz os resultados desta pesquisa para uma propositura de que as gestões locais e seu corpo diretivo não conseguiu perceber, ainda, as redes sociais como um meio comunicativo de promoção de democracia participativa.

Quanto aos modelos de comunicação constata-se que as gestões municipais examinadas neste estudo ainda privilegiam a forma monológica de se comunicar com a sociedade. Ao mesmo tempo, os achados demonstram que as fanpages estão sendo utilizadas, ilogicamente, para estabelecer uma comunicação de mão única, predominando o ato de informar. As administrações fazem pouco ou quase nenhum uso do modelo dialógico, quando o ouvir se faz proeminente e necessário no processo participativo.

Após entregar o objetivo proposto pelo estudo, cabe destacar alguns apontamentos que geraram indagações, levantados no transcorrer da pesquisa e que podem servir de insights para pesquisas futuras.

A primeira ocorrência é o fato de os órgãos pesquisados utilizarem muito pouco os recursos do Facebook. Escassas foram as postagens em forma de transmissão ao vivo, enquetes, 
questionários, fóruns, grupos de discussão, utilização de "hashtag" para monitoramento de temas de interesse da municipalidade, dentre outros. Essas funcionalidades da ferramenta poderiam ser fortemente utilizadas para promover a accountability com participação virtual.

Outro ponto que se destaca é a linguagem estabelecida nas fanpages das prefeituras analisadas. A comunicação nas redes sociais demanda a adaptação da linguagem nos posts realizados na hipótese de a informação ter sido retirada de canais tradicionais de comunicação, como, por exemplo, do portal da transparência ou do portal institucional das gestões públicas. As informações não devem ser migradas de forma mimética para o Facebook; é importante que seja realizada uma modificação da linguagem para a rede social, utilizando, por exemplo, o regionalismo, o humor e uma narrativa mais coloquial, tornando a publicação mais atrativa e mais compreensiva para o usuário.

Um último ponto merecedor de ser trazido para esta conclusão é o fato de se encontrar, nas fanpages pesquisadas, a disponibilidade das gestões locais em promover uma aproximação e um diálogo com a sociedade, conquanto, fora do contexto da unidade de análise deste estudo. Isso pôde ser percebido em postagens em que as administrações públicas incentivavam a sociedade interagir com ela em determinadas datas ou eventos como: campanhas do dia dos namorados, dia das mães, solicitação de envio de fotos, curiosidades sobre a cidade, entre outros. Fica nesse cenário a indagação: por que não agir da mesma forma quando em se tratando de práticas de accountability com participação?

NOTA:

1 O termo affordance não possui tradução para o português. Nesta pesquisa é adotado o conceito desenvolvido por James Gibson em 1977 para demonstrar as qualidades de um objeto, que permite ao ator reconhecer suas funcionalidades através dos seus atributos, de forma intuitiva, sem explicação.

\section{REFERÊNCIAS}

ALLEGRETTI, D. S; PLATT NETO, O. A. Funcionalidades, limitações e potencialidades do Portal da Transparência do Estado do Rio Grande do Sul. Revista Catarinense da Ciência Contábil - CRCSC, Florianópolis, v. 9, n. 26, p. 79-95, abr./jun. 2010.

ANGELI, D. W. S. Accountability e internet numa perspectiva comparada: a atuação digital das controladorias públicas na América Latina. 2017. Dissertação (Mestrado em Ciência Política) Universidade Federal do Paraná, Curitiba. 
ANTUNES, M. T. P.; OCTAVIO NETO, R. de. M.; VIEIRA, A. M. Pesquisa Intervencionista e Mestrados Profissionais: perspectivas de sua prática nos cursos da área de gestão. Indagatio Didactica, v. 8, n. 3, p.53-68, out. 2016.

ARNSTEIN, S. R. A Ladder of Citizen Participation. JAIP, v. 35, n. 4, p. 216-224, July. 1969.

BARDIN, L. Análise de conteúdo. Ed. rev. e ampl. São Paulo: Edições 70, 2013.

BERTOT, J. C.; JAEGER, P. T.; GRIMES, J. M. Promoting transparency and accountability through ICTs, social media, and collaborative e-government. Emerald, v. 6, n. 1, p. 78-91, Apr. 2011.

BOBBIO, N. Estado, governo, sociedade: por uma teoria geral da política. Tradução de Marco Aurélio Nogueira. Rio de Janeiro: Paz e Terra, 1987.

BONSÓN, E.; ROYO, S.; RATKAI, M. Citizens' engagement on local governments' Facebook sites. An empirical analysis: the impact of different media and content types in Western Europe.

Government Information Quarterly, 2014.

BOVENS, M. et al. Does public accountability work? An assessment tool. Public Administration, $v$. 86, n. 1, p. 225-242, 2008.

BOVENS, M. Two Concepts of Accountability: Accountability as a Virtue and as a Mechanism. West European Politics, v. 33, n. 5, p. 946-967, 10 Sep. 2010.

BRANDÃO, E. P. Conceito de Comunicação Pública. In: DUARTE, J. (Org.) Comunicação Pública: Estado, governo, mercado, sociedade e interesse público. São Paulo: Atlas, 2007.

BRASIL. Constituição da República Federativa do Brasil. Brasília, DF: 1988

BRASIL. Lei Complementar Federal no 101, de 4 de maio de 2000. Estabelece normas de finanças públicas voltadas para a responsabilidade fiscal e dá outras providências. Brasília, 2000. Disponível em: http://www.planalto.gov.br/ccivil_03/leis/lcp/lcp101.htm. Acesso em: 25 abr. 2018.

BRASIL. Lei no 12.527, de 18 de novembro de 2011. Dispõe sobre o acesso à informação. Brasília, 2011. Disponível em: http://www.planalto.gov.br/ccivil_03/_ato2011-2014/2011/lei/l12527.htm. Acesso em: 25 abr. 2018.

BRASIL. Lei no 131, de 27 de maio de 2009. Dispõe sobre as normas de finanças públicas voltadas para a responsabilidade na gestão fiscal e dá outras providências. Brasília, 2009. Disponível em: http://www.planalto.gov.br/ccivil_03/leis/lcp/lcp131.htm. Acesso em: 25 abr. 2018.

CAMPOS, A. M. Accountability: quando poderemos traduzi-la para o português? Revista da Administração Pública, Rio de Janeiro, v. 24, n. 2, fev./abr. 1990.

CARVALHO, E. M. de. Consequências econômicas da adoção compulsória das normas internacionais de contabilidade (IFRS) no custo de capital próprio das empresas brasileiras listadas na BM\&FBOVESPA. 2014. Tese (Doutorado em Administração) - Universidade Federal do Rio Grande do Sul, Porto Alegre.

CASTELLS, M. A sociedade em rede. 6. ed. São Paulo: Paz e Terra, 2002. 
COMITÊ GESTOR DA INTERNET - CGI. Pesquisa sobre o uso das tecnologias de informação e comunicação no setor público brasileiro: TIC governo eletrônico 2015. São Paulo: Comitê Gestor da Internet no Brasil, 2016.

CRESWELL, J. W. Investigação qualitativa e projeto de pesquisa: escolhendo entre cinco abordagens. Tradução de Sandra Mallmann da Rosa; revisão técnica: Dirceu da Silva - 3. ed. Porto Alegre: Penso, 2014.

DAMGAARD, B.; LEWIS, J. M. Accountability and Citizen Participation. In: Mark BOVENS, M.; GOODIN, R. E; SCHILLEMANS, T. The Oxford Handbook of Public Accountability. Oxford University, 2014.

DREYER, B. M. Relações Públicas na gestão das estratégias de comunicação organizacional na sociedade digitalizada: um estudo de caso da Nestlé Brasil S/A. 2014. Dissertação (Mestrado em Ciências da Comunicação) - Escola de Comunicações e Artes, Universidade de São Paulo.

DUARTE, J. Conceito de Comunicação Pública. In: DUARTE, J. (Org.) Comunicação Pública: Estado, governo, mercado, sociedade e interesse público. São Paulo: Atlas, 2007.

EISENHARDT, M. K. Agency theory: an assessment and review. The Academy of Management Review, vol. 14, n. 1, p. 57-74, 1989.

GOULART, M. S. B. Participação e accountability no controle social do orçamento público: o caso do conselho de desenvolvimento regional de Itajaí. 2011. Tese (Doutorado em Administração) Universidade Federal da Bahia, Salvador.

GRUNIG, J. E. Uma Teoria Geral das Relações Públicas: quadro teórico para o exercício da profissão. In: GRUNIG, J. E; FERRARI, A. M; FRANÇA, F. Relações Públicas: teoria, contexto e relacionamentos. São Caetano do Sul: Difusão Editora, 2009a.

GRUNIG, A. L; GRUNIG, J. E; FERRARI, A. M. Perspectivas do "Excellence study" para a comunicação nas organizações. In: KUNSCH, M. M. K. (org.). Relações Públicas e Comunicação organizacional: campos acadêmicos e aplicados de múltiplas perspectivas. São Caetano do Sul: Difusão, 2009b.

IBGE. Pesquisa Nacional por Amostra de Domicílios Contínua - PNAD Contínua - 2016. Disponível em: https://www.ibge.gov.br/estatisticas-novoportal/sociais/trabalho/9171-pesquisa-nacional-poramostra-de-domicilios-continua-mensal.html?=\&t=downloads. Acesso em: 14 jun. 2018.

JAHNS, F. T.; RAUPP, F. M. Transparência do Poder Executivo dos Estados Brasileiros. Revista Universo Contábil, ISSN 1809-3337, FURB, Blumenau, v. 12, n. 3, p. 65-72, jul./set. 2016.

KLEIN, R. H. Mecanismos de ampliação da transparência em portais de dados abertos governamentais brasileiros à luz da accountability theory. 2017. Tese (Doutorado em Administração) - Pontifícia Universidade Católica do Rio Grande do Sul, Porto Alegre.

LAVALLE, A. G.; VERA, E. I. A trama da crítica democrática: da participação à representação e à accountability. Lua Nova, São Paulo, n. 84, p. 353-364, 2011.

LÓPEZ, J. C. J. Modelo de comunicación pública organizacional e informativa para entidades del estado. Bogotá: USAID-CASALS\&Associates, 2004. 
LÓPEZ, J. C. J. Proposta geral de comunicação pública. In: DUARTE, J. Comunicação pública: estado, mercado, sociedade e interesse público. 3. ed. São Paulo: Atlas, 2012.

MAGRO, M. J. A Review of Social Media Use in E-Government. Administrative Sciences. v. 2, p.148161, abr. 2012.

MAINWARING, S. Introduction: Democratic accountability in Latin America. Oxford: Oxford University Press (Oxford Studies in Democratization), 2003.

MARQUES, F. P. J. A. (2014). Internet e Transparência Política. Trabalho apresentado ao Grupo de Trabalho Comunicação e Política do XXIII Encontro Anual da Compós, na Universidade Federal do Pará, Belém de 27 a 30 de maio de 2014.

MARTINS, G. de. A. Estudo de caso: uma estratégia de pesquisa. São Paulo: Atlas, 2006.

MATOS, H. Comunicação pública, esfera pública e capital social. In: DUARTE, J. (Org.) Comunicação Pública: Estado, governo, mercado, sociedade e interesse público. São Paulo: Atlas, 2007.

MERGEL, I. A framework for interpreting social media interactions in the public sector. Government Information Quarterly, v. 30, p. 327-334, 2013.

NASCIMENTO, L. L. do. Processo e práticas de comunicação em empresas públicas da esfera federal: análise das redes sociais digitais. 2014. Dissertação (Mestrado em Ciências da Comunicação) Escola de Comunicações e Artes, Universidade de São Paulo.

NOGUEIRA, J. P. F.; CASTRO, C. P. Internet, Democracia e Comunicação de Governo - análise do conteúdo da página do Facebook do Portal Brasil da Presidência da República. Rev. Estud. Comum., v. 15, n. 37, p. 134-151, jan./mar. 2014.

O'DONNELL, G. Accountability horizontal e novas poliarquias. Lua Nova: Revista de Cultura e Política, n. 44, São Paulo, 1998.

PERUZZOTTI, E; SMULOVITZ, C. (Org.). Controlando la Política. Ciudadanos y Medios en las Democracias Latinoamericanas. Buenos Aires: Grupo Editorial Temas, 2002.

PICAZO-VELA, S.; GUTIÉRREZ-MARTÍNEZ, I.; LUNA-REYES, L. F. Understanding risks, benefits, and strategic alternatives of social media applications in the public sector. Government Information Quarterly, v. 29, p. 504-511, Aug. 2012.

PINHO, J. A. G. de. Investigando portais de governo eletrônico de estados no Brasil: muita tecnologia, pouca democracia. Revista de Administração Pública - RAP, Rio de Janeiro, v. 42, n. 3, p. 471-493, mai./jun. 2008.

PINHO, J. A. G. de; SACRAMENTO, A. R. S. Accountability: já podemos traduzi-la para o português? Revista de Administração Pública - RAP, Rio de Janeiro, v. 43 n. 6, p. 1343-1368, nov./dez. 2009.

PLATT NETO, O. A. Construção de um modelo para avaliação da transparência da gestão pública municipal com vistas a favorecer o controle social. 2005. Tese (Doutorado em Engenharia de Produção) - Programa de Pós-graduação em Engenharia de Produção, Universidade Federal de Santa Catarina, Florianópolis. 
PLATT NETO, O. A. et al. Publicidade e Transparência das Contas Públicas: obrigatoriedade e abrangência desses princípios na administração pública brasileira. Contab. Vista \& Rev., v. 18, n. 1, p. 75-94, jan./mar. 2007.

PRETTY, J. N. et al. A Trainer's Guide for Participatory Learning and Action. London, 1995.

RAUPP, F.M.; PINHO, J. A. G. de. Accountability em câmaras municipais: uma investigação em portais eletrônicos. R. Adm., São Paulo, v. 48, n. 4, p. 770-782, out./nov./dez. 2013.

RECUERO, R. Redes Sociais na Internet. Porto Alegre: Sulina, 2009.

ROCHA JR, F. R. Mídias Sociais e Transparência: uma análise dos maiores municípios brasileiros. 2017. Dissertação (Mestrado em Ciências Contábeis) - Centro de Ciências Jurídicas e econômicas da Universidade Federal do Espírito Santo.

ROLANDO, Stefano. A dinâmica evolutiva da comunicação pública. In: KUNSCH, M. M. K. (Org.). Comunicação pública, sociedade e cidadania. São Caetano do Sul, SP: Difusão, 2011.

ROSA, R.; RUSSEL, R. O desafio das organizações nas redes sociais: um olhar no Twitter da Natura, da Vivo e do Submarino. V ABRACORP, 2011.

SANTOS. V. L. P. dos; COSTA, C. J. de. S. A. A observação on-line como instrumento investigativo: uma experiência utilizando fórum de discussão. Debates em Educação. v. 7, n. 14, p. 56, 2015.

SANTOS. E. M. dos; SILVA, A. S. R. Mídias sociais no setor público: uma análise do uso como ferramentas de comunicação e interação em organizações no Brasil. Conf-IRM 2017. Proceedings, 2017.

SCHEDLER, A. Conceptualizing Accountability. In: SCHEDLER, A.; DIAMOND, L.; PLATTNER, M. F. (Eds.). The Self-Restraining State: Power and Accountability in New Democracies. Boulder: Lynne Rienner Publishers Inc., p. 13-28, 1999.

STAMATI, T.; PAPADOPOULOS, T.; ANAGNOSTOPOULOS, D. Social media for openness and accountability in the public sector: Cases in the Greek contexto. Government Information Quarterly, v. 32, p. 12-29, Dec. 2014.

STATISTA. Portal de estatística. Disponível em: https://www.statista.com/statistics/272014/globalsocial-networks-ranked-bynumber-of-users/. Acesso em: 27 fev. 2018.

TERRA, C.F. Mídias Sociais... e agora?: O que você precisa saber para implementar um projeto de mídias sociais. São Caetano do Sul: Difusão Editora; Rio de Janeiro: Editora Senac Rio, 2011.

UNIÃO INTERNACIONAL DE TELECOMUNICAÇÕES (UIT). ICT Facts and Figures 2017. Genebra, 2017 Disponível em: https://www.itu.int/en/ITU-D/Statistics/Documents/facts/ICTFactsFigures2017.pdf. Acesso em: 26 fev. 2018.

WATERS, R. D. et al. Engaging stakeholders trough social networking: How nonprofit organizations are using Facebook. Public Relations Review. v. 35, p. 102-106, 2009.

ZÉMOR, P. La Communication Publique. PUF, Col. Que sais-je? Tradução resumida do livro Profa. Dra. Elizabeth Brandão. Paris, 1995. 
ZHENG, L.; ZHENG, T. Innovation through social media in the public sector: Information and interactions. Government Information Quarterly, 2014.

Trabalho enviado em 01 de julho de 2019

Enviado em 01 de outubro de 2019 